\title{
YO TAMBIÉN QUIERO COMPETIR: LAS BARRERAS DE ENTRADA Y DE PERMANENCIA Y EL PROCEDIMIENTO DE ELIMINACIÓN DE BARRERAS BUROCRÁTICAS
}

\author{
I ALSO WANT TO COMPETE: THE BARRIERS TO ENTRY \\ AND PERMANENCE AND THE PROCEDURE FOR REMOVING \\ BUREAUCRATIC BARRIERS
}

\author{
César Rodrigo Carrillo Temple* \\ Rodrigo, Elías \& Medrano Abogados
}

\begin{abstract}
The exercise of the constitutional economic rights of free private initiative and freedom of enterprise may be justifiably limited by objective and reasonable limits established in regulation or imposed by the operation of the market itself. Nonetheless, such rights may be unjustifiably restricted by anti-competitive practices, regulations that contradict the legal system, or the imposition of unnecessary demands and limitations by the Government.
\end{abstract}

In this context, the current regulatory framework in Peru establishes various mechanisms to control the different types of barriers to entry and permanence in the market, among which is the system of elimination of bureaucratic barriers, regulated by Legislative Decree 1256. In order to understand this system and its proper application, the author delimits the scope and particularities of the concept of bureaucratic barrier, as well as the requirements and demands for the individuals to report and prove the existence of illegal and/ or unreasonable bureaucratic barriers before the Peruvian Competition Agency.

KEYWORDS: Entry barriers; permanence barriers; regulation; competitiveness; elimination of bureaucratic barriers.
El ejercicio de los derechos constitucionales económicos de libre iniciativa privada y libertad de empresa puede verse limitado de manera justificada por límites objetivos y razonables previstos en la regulación o impuestos por el propio funcionamiento del mercado. Sin embargo, tales derechos pueden verse restringidos de manera injustificada por prácticas anticompetitivas, regulaciones contradictorias con el ordenamiento jurídico o la imposición de exigencias y limitaciones innecesarias por parte del Estado.

En ese contexto, el marco normativo vigente en el Perú establece diversos mecanismos de control de las distintas clases de barreras de entrada y de permanencia en el mercado, dentro de los cuales se encuentra el sistema de eliminación de barreras burocráticas, regulado actualmente por el Decreto Legislativo 1256. A efectos de comprender este sistema y su correcta aplicación, el autor delimita el alcance y particularidades del concepto de barrera burocrática, así como los requisitos y exigencias para que los administrados puedan denunciar y acreditar la existencia de barreras burocráticas ilegales o carentes de razonabilidad ante el Indecopi.

PALABRAS CLAVE: Barreras de entrada; barreras de permanencia; regulación; competitividad; eliminación de barreras burocráticas.

\footnotetext{
Abogado. Miembro fundador del Círculo de Estudios de Derecho de la Competencia de la Universidad de Lima. Asociado del área de Regulación de Servicios Públicos y Libre Competencia del Estudio Rodrigo, Elías y Medrano Abogados (Lima, Perú). Contacto: ccarrillo@estudiorodrigo.com.
}

Nota del Editor: Este artículo fue recibido por el Consejo Ejecutivo de THËMIS-Revista de Derecho el 2 de julio de 2020, y aceptado por el mismo el 29 de octubre de 2020. 


\section{MODELO ECONÓMICO CONOCIDO, PERO CONDICIONES DE COMPETENCIA NO SIEM- PRE CONSIDERADAS}

El régimen económico constitucional peruano reconoce el deber del Estado de estimular la creación de riqueza, y de garantizar la libre iniciativa privada y la libertad de empresa; así como de facilitar y vigilar la libre competencia ${ }^{1}$. Si bien tales principios son generalmente conocidos, no siempre se considera que, para que exista libre competencia, la estructura del mercado y el comportamiento de los agentes económicos -incluyendo al Estado, las empresas y los consumidores-deben permitir que la iniciativa privada se desarrolle de manera adecuada, dentro de límites razonables y que promuevan la eficiencia en el mercado, pese a que pueda resultar complejo delimitar cuáles son esos límites o en qué consiste la eficiencia en el mercado en cada caso particular.

Lo que sí es claro es que, bajo un modelo de economía social de mercado, el ejercicio de los derechos de libre iniciativa privada y de libertad de empresa no es ilimitado y que la intervención del Estado en la economía no debería impedir injustificadamente el acceso o permanencia de competidores en el mercado. Por el contrario, su actuación debería estar enfocada en promover y facilitar la competencia, ponderando los intereses públicos con los intereses privados.

En ese contexto, el marco normativo peruano prevé mecanismos para la prevención y eliminación de regulaciones y actuaciones estatales que impidan o dificulten el desarrollo de las actividades económicas de manera injustificada. Uno de tales mecanismos es el procedimiento administrativo de eliminación de barreras burocráticas, seguido ante los órganos competentes del Instituto Nacional de Defensa de la Competencia y de la Protección de la Propiedad Intelectual (en adelante, Indecopi), actualmente regulado por el Decreto Legislativo 1256, Decreto Legislativo que aprueba la Ley de Prevención y Eliminación de Barreras Burocráticas (en adelante, DL 1256).

Este último mecanismo permite el control posterior (ex post) de regulaciones materializadas en disposiciones administrativas, actos administrativos y actuaciones materiales de distintas esferas de la Administración Pública, incluso del ámbito municipal, que impongan barreras ilegales o carentes de razonabilidad.

No obstante, pese a los esfuerzos y mecanismos implementados por el Estado a la fecha, es posible observar que continúan existiendo -y se continúan emitiendo- barreras burocráticas en el Perú ${ }^{2}$ y que las denuncias presentadas por los administrados ante Indecopi para su eliminación o inaplicación no siempre cumplen con los requisitos de admisibilidad o de fondo para lograr tales objetivos ${ }^{3}$. En ese sentido, es válido analizar los alcances y posibilidades de mejora de la regulación vigente sobre eliminación de barreras burocráticas y los criterios que vienen siendo aplicados por los órganos del Indecopi en la práctica.

En particular, es relevante considerar que el procedimiento de eliminación de barreras burocráticas presenta diferencias respecto a otros mecanismos e investigaciones en defensa de la competencia. Como será explicado más adelante, en este procedimiento trascienden intereses públicos en el aumento de la competitividad del país para atraer o permitir el desarrollo de las inversiones, además de los beneficios que trae para

Como es conocido, la Constitución Política del Perú reconoce, entre otros aspectos:

Artículo 58.- La iniciativa privada es libre. Se ejerce en una economía social de mercado. Bajo este régimen, el Estado orienta el desarrollo del país, y actúa principalmente en las áreas de promoción de empleo, salud, educación, seguridad, servicios públicos e infraestructura.

Artículo 59.- El Estado estimula la creación de riqueza y garantiza la libertad de trabajo y la libertad de empresa, comercio e industria. El ejercicio de estas libertades no debe ser lesivo a la moral, ni a la salud, ni a la seguridad públicas. El Estado brinda oportunidades de superación a los sectores que sufren cualquier desigualdad; en tal sentido, promueve las pequeñas empresas en todas sus modalidades.

$[\ldots]$

Artículo 61.- El Estado facilita y vigila la libre competencia. Combate toda práctica que la limite y el abuso de posiciones dominantes o monopólicas. Ninguna ley ni concertación puede autorizar ni establecer monopolios [...] (1993).

2 Al respecto, la Organización para la Cooperación y el Desarrollo Económicos (en adelante, OCDE) ha reconocido recientemente que

[l]a evaluación ex post sigue siendo incipiente en el Perú. La evaluación de las reglamentaciones existentes se centra en gran medida en la reducción de las cargas administrativas y en la simplificación administrativa. Las evaluaciones realizadas actualmente no permiten determinar si las reglamentaciones existentes están logrando sus objetivos. En ese sentido, sería beneficioso que los organismos reguladores realizaran evaluaciones sistemáticas de las reglamentaciones para determinar si siguen siendo adecuadas para su propósito (OCDE, 2020).

3 Esta problemática será analizada en la sección $\mathrm{V}$ del presente artículo. 
la promoción de la competencia y el bienestar de los ciudadanos en general ${ }^{4}$.

Por ello, mediante el presente artículo se busca reconocer la ubicación, las particularidades, el alcance, los fines y la importancia del sistema de eliminación de las barreras burocráticas, con la finalidad de analizar la efectividad del mismo y formular propuestas para su aplicación adecuada. Específicamente, en el presente artículo se llamará la atención sobre la participación de los administrados a través de la presentación de denuncias para eliminación o inaplicación de barreras burocráticas ilegales o irracionales.

\section{QUIERO ENTRAR A COMPETIR: LAS BARRE- RAS DE ENTRADA AL MERCADO}

En primer lugar, es necesario delimitar a qué nos referimos cuando hablamos de barreras de entrada y barreras de permanencia en el mercado. Al respecto, debemos adelantar que el concepto de barrera burocrática es una especie particular dentro de tales categorías, encontrándose delimitado expresamente por el DL 1256, por lo que goza de características específicas.

Sin perjuicio de lo anterior, podemos empezar analizando el concepto de barrera de entrada al mercado. De manera general y en términos económicos, se ha señalado que una barrera de entrada es una condición que impone a un nuevo entrante costos de producción más altos que los soportados por las empresas que ya son participantes en el mercado (Stigler, 1968; Posner, 2001). A partir de la definición citada, y como se puede advertir, la generación de mayores costos de producción a nuevos competidores en el mercado puede originarse en distintos niveles y por distintos factores.

Por ejemplo, en el caso de una empresa que busca entrar a competir en el mercado de comercialización de bebidas no alcohólicas en Lima, esta debe enfrentarse a una serie de dificultades para empezar a realizar actividades en dicho mercado, como: (i) las posibles estrategias de los competidores ya establecidos en el mercado, destinadas a no perder a sus clientes actuales; (ii) la obtención de autorizaciones sanitarias; (iii) la obtención de títulos habilitantes para el funcionamiento de locales; (iv) la constitución del vehículo corporativo (sociedad $\mathrm{u}$ otro) para realizar sus actividades empresariales; ( $v$ ) la presentación de documentación ante distintas autoridades; (vi) las inversiones en la publicidad inicial del negocio; (vii) entre otras.

Evidentemente, muchos de estos factores pueden ser dificultades comunes al inicio de cualquier emprendimiento, por lo que podrían considerarse barreras naturales para entrar al mercado. Sin embargo, algunas de estas complejidades pueden ser el resultado de prácticas anticompetitivas, regulaciones ilegales o la exigencia de requisitos innecesarios por parte de la Administración Pública. Así, las barreras de acceso o de entrada al mercado constituyen un concepto amplio, estudiado por distintas entidades estatales para promover el desarrollo de las inversiones y actividades económicas en el país, incluyendo a diferentes áreas del Indecopi.

Como muestra de ello, la Comisión de Defensa de la Libre Competencia del Indecopi (en adelante, CLC) ha desarrollado que el concepto de barreras de entrada se refiere a "aquellos factores que limitan la entrada de nuevos competidores y permiten que las firmas establecidas puedan elevar los precios de manera sostenida, por encima de los niveles que regirían en un entorno competitivo" (Resolución 078-2016/CLC-INDECOPI, 2016, p. 244). No obstante, no debe confundirse esta noción general con el concepto específico de barreras burocráticas regulado por el DL 1256.

En esa misma línea, el artículo 7 del Texto Único Ordenado de la Ley de Represión de Conductas Anticompetitivas, aprobado mediante Decreto Supremo 030-2019-PCM (en adelante, la LRCA), reconoce la posibilidad de que puedan existir diversos tipos de barreras de entrada en un mercado específico, en tanto señala como un factor para considerar que un agente económico goza de posición de dominio, entre otros, a la existencia de barreras de entrada de tipo legal, económica o estratégica (2019).

Entonces, es necesario comprender el universo de posibles barreras de acceso al mercado, para así delimitar los mecanismos dirigidos a su detección y posible eliminación, lo cual permitirá entender sus alcances e importancia en cada caso concreto. A continuación, en función a criterios seguidos

\footnotetext{
Ello ha sido reconocido en distintas oportunidades por las entidades del Gobierno Central e, inclusive, por el Tribunal Constitucional del Perú respecto a los antecedentes normativos del DL 1256. Así, el supremo intérprete de la Constitución Política del Perú ha indicado: "[c]omo es de verse preliminarmente, la Comisión se desenvuelve dentro del ámbito del control de la legalidad de determinadas actividades que pueden afectar la competitividad general en el territorio nacional y por ende el propio y normal desarrollo de la libertad de empresa o de comercio" (Expediente 00014-2009-PI/ TC, 2010).
} 
por el Indecopi y desarrollados por la literatura económica y legal, proponemos una clasificación de las barreras de entrada al mercado según su naturaleza u origen.

\section{A. Las barreras estratégicas a la entrada de nuevos competidores}

Por un lado, cabe diferenciar aquellas barreras -entendidas como impedimentos o dificultadesque son impuestas por las demás empresas que concurren en el mercado (empresas ya establecidas), alterando el proceso competitivo y a las cuales nos referíamos al citar la definición de barreras de entrada esbozada por la CLC.

Esta clase de barreras de entrada al mercado son llamadas barreras estratégicas y han sido definidas como "aquellas voluntarias e intencionalmente exigidas por el propio comportamiento de las empresas para reducir o impedir que se produzca la entrada de un competidor" (Flint Blanck, 2002, p. 227).

En palabras precisas de la Secretaría Técnica de la CLC:

Las barreras estratégicas o de conducta se refieren a comportamientos empresariales que restringen o disuaden a las empresas a entrar en la industria. Las empresas establecidas pueden llevar a cabo diversas prácticas con el objetivo de influir negativamente sobre los beneficios esperados del o los entrantes. El éxito de dichas prácticas dependerá, entre otros aspectos, de que las amenazas resulten creíbles para la empresa entrante así como de que puedan mantenerse en el tiempo sin que existan prácticas alternativas más convenientes para la empresa establecida. Estas prácticas pueden estar orientadas a la reducción o eliminación de los beneficios esperados de la empresa entrante o a elevar los costos de entrada u operación en el mercado. Son ejemplos de barreras estratégicas: los precios límite, la sobre-inversión en capacidad, la diferenciación de productos, los subsidios cruzados, la integración y restricciones verticales, el incremento de los costos de los rivales, los precios predatorios, etc. (Informe 035-2004-INDECOPI/ST-CLC, 2004, p. 39).
En ese contexto, ante este tipo de comportamientos, los agentes económicos pueden recurrir a la CLC y a su Secretaría Técnica para que, en el marco de la LRCA, denuncien y se investigue la existencia y eventuales responsabilidades por la comisión de prácticas anticompetitivas, tomando en consideración la capacidad efectiva o potencial de los agentes para producir restricciones al acceso al mercado. Es decir, no siempre una barrera estratégica será considerada como una práctica anticompetitiva, ya que puede ser que no cumpla con los requisitos establecidos en la LRCA para sancionar a los agentes económicos, como es el caso de las prohibiciones relativas, sobre las cuales se realiza un balance de efectos de la conducta para determinar si produce o puede producir afectación a la competencia y a los consumidores.

En los procedimientos seguidos ante la CLC para la detección y represión de la imposición de barreras estratégicas de acceso al mercado, la carga de la prueba recae en el órgano instructor $-y$, de ser el caso, con la colaboración del denunciante ${ }^{5}-$ para acreditar la necesidad de reprimir la conducta anticompetitiva. Como veremos más adelante, en los procedimientos de eliminación de barreras burocráticas, la carga de la prueba tiene reglas particulares justificadas en la naturaleza y fines de tales procedimientos.

\section{B. Las barreras estructurales a la entrada al mercado}

Existe otro tipo de barreras cuyo origen no se encuentra en el comportamiento de las empresas, sino que son el resultado de las características estructurales del mercado en el que se va a desarroIlar la actividad económica, tales como los costos, la demanda y el estado de la tecnología (OCDE, 2005). Así, se formula el concepto de barreras estructurales, las cuales pueden ser divididas en (i) barreras económicas; y, (ii) barreras legales.

Cabe indicar que algunos autores prescinden de agrupar a estas dos últimas subclasificaciones como barreras estructurales y optan por referirse a las barreras económicas como barreras naturales y en una categoría independiente estudiar a las barreras legales (Paredes \& Tarziján, 2006, p. 84).

\footnotetext{
El artículo 18 de la LRCA es claro al señalar:
}

18.1. El procedimiento sancionador de investigación y sanción de conductas anticompetitivas se inicia siempre de oficio, bien por iniciativa de la Secretaría Técnica o por denuncia de parte.

18.2. En el procedimiento sancionador promovido por una denuncia de parte, el denunciante es un colaborador en el procedimiento de investigación, conservando la Secretaría Técnica la titularidad de la acción de oficio.

18.3. El procedimiento sancionador podrá ser iniciado cuando la conducta denunciada se está ejecutando, cuando exista amenaza de que se produzca e, inclusive, cuando ya hubiera cesado sus efectos.

[...] (2019). 
Sin embargo, en tanto las barreras legales generan costos fijos que forman parte de la estructura del mercado, consideramos, siguiendo a la OCDE, que tanto las barreras económicas como las legales pueden ser agrupadas dentro de la clasificación de barreras estructurales:

Including regulatory barriers in the structural conditions section rather than in the strategic behaviour section may seem overly optimistic to some readers. It is certainly true that many companies have successfully manipulated regulatory regimes for the purpose of deterring entry. Unless the regulation itself is being challenged, however, why regulation exists is not as important as that it exists ${ }^{6}$ (OCDE, 2005, p. 33).

Lo anterior nos lleva a recoger la presente clasificación en un plano del ser y no, por el momento, del deber ser. Sin embargo, cabe preguntarse si las barreras estructurales son efectivamente naturales en la competencia. Es decir, si cada una de estas posibles barreras forman parte de la estructura misma del mercado porque la naturaleza de la actividad económica así lo determina o si, por el contrario, son dificultades innecesarias que podrían ser de cierto modo disminuidas o eliminadas para promover la libre competencia. Dejando de lado por el momento la reflexión anterior, corresponde observar las principales características de estas barreras a la entrada al mercado.

\section{Las barreras económicas}

Estas barreras se presentan como consecuencia de las condiciones económicas en las que se desarrolla cierta actividad en un mercado específico. Este concepto también ha sido recogido por la CLC y su Secretaría Técnica, habiendo reconocido esta última que

[l]as barreras económicas se relacionan a las ventajas absolutas en costos, la presencia de economías de escala y de ámbito significativos, las características de la tecnología requerida, la existencia de facilidades esenciales y los costos hundidos o irrecuperables en que debe incurrir una empresa para ingresar a una industria (Informe 035-2004-INDECOPI/ ST-CLC, 2004, p. 39) ${ }^{7}$.

Como se ha señalado, las barreras económicas pueden ser estudiadas bajo la denominación de barreras naturales, por lo que se sostiene que estas se manifiestan cuando la estructura del mercado, en un momento determinado, permite a las empresas establecidas enfrentarse a menores costos que pueden provenir de sinergias operacionales como son las economías de escala y las economías de ámbito (Paredes \& Tarziján, 2006, pp. 84-85).

En consecuencia, la presencia de barreras económicas puede dificultar la entrada de nuevos competidores en el mercado, generar monopolios u oligopolios naturales e, incluso, producir ausencia de inversión privada en algunos mercados. Es por ello que, en ciertas ocasiones, el Estado emite regulaciones para promover la competencia o realiza procesos de promoción de la inversión privada en mercados con barreras económicas de entrada altas.

\section{Las barreras legales}

Las barreras legales son aquellas restricciones impuestas por las distintas entidades del Estado para el desarrollo de las actividades económicas. Por lo tanto, se incluye en esta categoría a todas las exigencias y limitaciones normativas impuestas por los distintos niveles del gobierno y poderes del Estado, tales como las prohibiciones para realizar ciertas actividades, la obtención de permisos y licencias, el cumplimiento de regulaciones y estándares, el pago de tributos, entre otros.

Debemos precisar que esta clase de barreras son llamadas legales en una concepción amplia de dicha palabra. En efecto, este concepto no se refiere únicamente a limitaciones cuyo origen se encuentra en la ley, sino en el marco normativo en general y a través de las distintas modalidades de intervención del Estado en la economía, incluyendo normas infra legales, actuaciones y actos administrativos.

Es en esta categoría en la que podemos ubicar al concepto de barrera burocrática regulado por el

$6 \quad$ Incluir las barreras legales en la sección de condiciones estructurales más que en la de comportamiento estratégico puede parecer demasiado optimista para algunos lectores. Es cierto que muchas empresas han manipulado con éxito los regímenes regulatorios con el fin de impedir la entrada al mercado. Sin embargo, a menos que se cuestione la propia regulación, el porqué de la existencia de la regulación no es tan importante como su existencia (OCDE, 2005, p. 33) [traducción libre].

7 La CLC también ha recogido esta clasificación. Por ejemplo, en la Resolución 026-2010/CLC-INDECOPI del 3 de mayo de 2010, al analizar el mercado de servicios de transporte ferroviario en el Ferrocarril Sur-Oriente, la CLC señaló que "[l]as barreras económicas se encuentran representadas por la fuerte inversión que debe realizarse para la adquisición del material tractivo y rodante, el cual no es de fácil aprovisionamiento ni puede ser utilizado en otras vías, debido a las particularidades topográficas de la zona en la que se encuentra el FSO" (2010). 
DL $1256^{8}$, al que nos referiremos más adelante. El análisis de ilegalidad o irracionalidad contemplado en el referido decreto legislativo, así como la eventual inaplicación de la norma denunciada, es de competencia de la Comisión de Eliminación de Barreras Burocráticas del Indecopi (en adelante, CEBB) en primera instancia y de la Sala Especializada en Eliminación de Barreras Burocráticas (en adelante, SEBB) en segunda instancia.

Por otro lado, en esta categoría también se encuentran las barreras arancelarias y las barreras comerciales no arancelarias en el comercio internacional, las cuales se encuentran materializadas en las disposiciones gubernamentales que limitan la importación o exportación de bienes en el país.

Respecto a las barreras comerciales no arancelarias, la Comisión de Dumping, Subsidios y Eliminación de Barreras Comerciales No Arancelarias del Indecopi (en adelante, CDB) efectúa el control y eliminación de

[t]oda exigencia, requisito, restricción, prohibición o cobro establecido por cualquier entidad de la Administración Pública en ejercicio de potestades de imperio o administrativas, carentes de legalidad o razonabilidad, que afecten la importación o exportación de bienes, desde o hacia el territorio nacional (Decreto Legislativo 1212, 2015, art. 7)

La CDB realiza dichas labores en primera instancia y la Sala Especializada en Defensa de la Competencia en segunda instancia.

Respecto a las barreras arancelarias, estas no están sujetas a la labor de control posterior y eliminación por parte del Indecopi. Ello, en la medida que los aranceles son impuestos que gravan las mercancías que se importan en el territorio nacional, reflejando una decisión de política fiscal que no puede ser evaluada por la CDB ni la CEBB, pues estas no cuentan con facultades para evaluar la política tributaria del Estado ((Insituto Nacional de Defensa de la Competencia y de la Protección de la Propiedad Intelectual [Indecopi], 2020, p. 3).
Sin embargo, no debe olvidarse que el cobro de tributos también implica la asunción de costos que pueden dificultar la entrada y permanencia de las empresas en ciertos sectores económicos.

Cabe señalar que las barreras legales -en generalno son negativas per se, incluyendo a las barreras burocráticas, debido a que la regla general debe ser que la intervención del Estado en la economía sirva a algún objetivo necesario y justificado. Así, es sumamente importante que "las entidades de la Administración Pública, incluido el Congreso de la República, orienten su accionar a principios rectores que permitan regulaciones necesarias y proporcionadas" (Patroni Vizquerra, 2011, p. 305).

Asimismo, el hecho de que una barrera legal califique como una barrera burocrática no implica que la misma sea negativa para el mercado y deba ser eliminada. Al respecto, Luna comenta lo siguiente:

[...] si bien el término barrera burocrática podría connotar negatividad y, por ende, hiciera suponer que todas las barreras deberían eliminarse, ello no es así. Únicamente debería eliminarse aquella medida que - luego de ser analizada - sea declarada ilegal o carente de razonabilidad. Aquella barrera que resulta compatible con el interés privado (el desarrollo de actividades económicas por los particulares y/o que la normas y principios de la simplificación administrativa) y el interés público no debe inaplicarse ni eliminarse (2019, p. 42)

De este modo, se tiene la premisa de que toda regulación estatal debe haber sido emitida de manera justificada con base en un análisis de impactos, costos y beneficios, coherencia con el ordenamiento jurídico, entre otros aspectos (OCDE, 2016, p. 14). Tales acciones se encuentran dentro del ámbito de la prevención y se ven reflejados en mecanismos de control previo (ex ante) de calidad normativa y regulatoria ${ }^{9}$, así como en las actividades de prevención de barreras burocráticas.

No obstante, algunas barreras legales pueden no haber seguido tales mecanismos ex ante o, inclu-

8 El artículo 3 de DL 1256 define al concepto de barrera burocrática de la siguiente manera:

3. Barrera burocrática: exigencia, requisito, limitación, prohibición y/o cobro que imponga cualquier entidad, dirigido a condicionar, restringir u obstaculizar el acceso y/o permanencia de los agentes económicos en el mercado y/o que puedan afectar a administrados en la tramitación de procedimientos administrativos sujetos a las normas y/o principios que garantizan la simplificación administrativa. La sola calidad de exigencia, requisito, limitación, prohibición y/o cobro no implica necesariamente su carácter ilegal y/o su carencia de razonabilidad (2016).

9 Mecanismos tales como: (i) las exigencias para la producción de normas, de acuerdo a la Ley 26889, Ley Marco para la Producción y Sistematización Legislativa, y su Reglamento aprobado mediante Decreto Supremo 008-2006-JUS; (ii) los mecanismos de calidad normativa previstos en la "Guía sobre la calidad normativa y publicación de proyectos normativos", aprobada mediante Resolución Directoral 008-2016-JUS/DGDOJ; (iii) el Análisis de Calidad Regulatoria de procedimientos administrativos, conforme al Decreto Legislativo 1310 y su Reglamento aprobado mediante Decreto Supremo 061-2019-PCM; y, (iv) los demás instrumentos para la mejora de la calidad regulatoria, conforme al Decreto Legislativo 1448. 
so, pueden no servir a algún objetivo socialmente meritorio o lo hacen de una manera que se desalienta innecesariamente la entrada al mercado (OCDE, 2005). En consecuencia, se hace necesaria la existencia de mecanismos de control posterior (ex post) de barreras legales, como pueden ser los procesos constitucionales regulados por el Código Procesal Constitucional ${ }^{10}$ y los procedimientos ante el Indecopi (tanto ante la CEBB como a la $\mathrm{CDB})$, cada uno dentro de su alcance y ámbito de aplicación específico.

En adición, el marco normativo peruano también prevé los mecanismos de abogacía de la competencia que puede llevar a cabo la CLC y su Secretaría Técnica, en virtud de la $\operatorname{LRCA}^{11}$, para sugerir, exhortar o recomendar a las entidades de la Administración Pública la implementación de medidas que restablezcan o promuevan la libre competencia, tales como la eliminación de barreras a la entrada. Por su parte, en el marco del DL $1256^{12}$, la CEBB o la SEBB pueden disponer que su respectiva Secretaría Técnica emita un informe técnico de abogacía para la eliminación de barreras contenidas en leyes, emitiendo recomendaciones sobre la implementación de medidas que promuevan la eliminación de tales barreras. Dicho informe es puesto en conocimiento del Congreso de la República o del Poder Ejecutivo, según corresponda.

\section{QUIERO SEGUIR COMPITIENDO: LAS BARRE- RAS DE PERMANENCIA EN EL MERCADO}

En línea con lo desarrollado anteriormente, cabe diferenciar teóricamente el concepto de las barreras de permanencia en el mercado, las cuales pueden afectar a agentes económicos ya establecidos, siguiendo la misma lógica y clasificación explicada para las barreras de entrada, salvo ciertas particularidades.

De hecho, no se suele diferenciar a las barreras de permanencia por considerarlas incluidas como manifestaciones de las barreras de entrada aplicadas a agentes económicos previamente constituidos, pero que podrían ver dificultada o restringida la continuación del desarrollo de sus actividades por comportamientos estratégicos de sus competidores, o por la modificación de las condiciones estructurales en las que venían participando en el mercado.

\section{A. Las barreras estratégicas a la permanencia en el mercado}

Las barreras estratégicas enfocadas en la permanencia en el mercado son originadas generalmente por prácticas contrarias a la libre y leal competencia por parte de empresas competidoras, a efectos de dificultar el desarrollo de las actividades económicas de sus competidores. Además, constituyen aquellas prácticas lícitas destinadas a captar la mayor cantidad de consumidores posibles y -como consecuencia natural- restar el éxito de las otras empresas que participan en el mismo mercado.

Así, en esta categoría encontramos a las prácticas exclusorias que, si bien pueden afectar a potenciales competidores para su acceso al mercado, en su mayoría se manifiestan como "conductas que implican intentos de excluir competidores para lograr un incremento o una mayor posibilidad de ejercer el poder de mercado, y pueden llevarse a cabo de diversas maneras" (Coloma, 2002, p. 1). Como se sabe, estas prácticas se encuentran prohibidas por la LRCA y, sobre ellas, el Tribunal de Defensa de la Competencia y la Propiedad Intelectual del Indecopi ha desarrollado que:

\section{[u]na práctica exclusoria es considerada como aquella cuyos efectos impactan principalmente en la estructura de mercado, o que apuntan a reforzar el poder de mercado de un dominante colocando en desventaja a otros competidores, por ejemplo, mediante la negativa a contratar o denegar el acceso a facilidades esenciales (Resolución 0708-2011-SC1-INDECOPI, 2011, pp. 6-7) $)^{13}$.}

Por otro lado, un factor adicional a ser considerado como parte de las barreras estratégicas de permanencia es la posibilidad de que se presenten actos de competencia desleal que puedan afectar la situación de otras empresas competidoras en el mercado.

En el Perú, los actos de competencia desleal se encuentran prohibidos por el Decreto Legislativo 1044, Ley de Represión de la Competencia Desleal

10 Nos referimos a: (i) el proceso de inconstitucionalidad; (ii) el proceso de acción popular; y, (iii) el proceso de amparo contra la aplicación de normas y actuaciones estatales.

11 Conforme a las competencias previstas en el inciso e) del numeral 14.2 del artículo 14 y el inciso g) del numeral 15.2 del artículo 15 de la LRCA.

12 Conforme al artículo 49 del DL 1256.

13 Cabe precisar que, si bien el procedimiento en el cual se emitió esta resolución analizó los alcances del Decreto Legislativo 701, derogado por la LRCA, la definición de prácticas exclusorias citada es útil y mantiene vigencia para explicar los alcances de dicho concepto. 
(en adelante, la LRCD), cuyo artículo 6 prohíbe de manera general cualquier acto que resulte objetivamente contrario a la buena fe empresarial que debe orientar la concurrencia en una economía social de mercado. En ese contexto, mediante esta clase de actos, las empresas pueden alterar el correcto funcionamiento del mercado. La autoridad encargada de velar por el cumplimiento de la LRCD es la Comisión de Fiscalización de Competencia Desleal del Indecopi en primera instancia, y la Sala Especializada en Defensa de la Competencia en segunda instancia.

\section{B. Las barreras estructurales a la permanencia en el mercado}

Estas barreras se originan por modificaciones en las condiciones en las que se venía desarrollando la actividad económica específica, siendo que tales modificaciones podrían originarse por fenómenos económicos (barreras económicas) o por nuevas regulaciones o actuaciones estatales (barreras legales).

\section{Las barreras económicas}

Las barreras económicas se presentan ante el cambio de circunstancias que determinaron el modelo económico o de negocio de una empresa, siendo que el desarrollo de sus actividades se enfrenta a dificultades como podrían ser el aumento de los costos e inversiones que se tienen que asumir para continuar operando en el mercado, al cambio de paradigmas en la tecnología, a la disponibilidad de materias primas, al cambio de necesidades y preferencias de los consumidores, entre otros.

\section{Las barreras legales}

Finalmente, encontramos a las barreras legales, originadas por la introducción de regulaciones que impongan límites, exigencias o restricciones para alguna actividad económica. Algunos ejemplos de estas son los cambios en las zonificaciones de los distritos, la imposición de nuevos límites a la antigüedad de vehículos, las exigencias de renovar licencias y la imposición de restricciones de horario para funcionamiento de locales (Guimaray Morales, 2018).

De esta manera, las barreras legales tienen un matiz particular cuando se trata de agentes ya constituidos en el mercado, pues se estaría afectando -de cierto modo y en distintos niveles- los derechos de propiedad y de libertad de empresa. En consecuencia, la introducción de regulaciones a la economía debe realizarse de manera legal y proporcional, siendo necesario analizar cada una de las regulaciones a ser emitidas por el Estado.
Es precisamente bajo la figura de las barreras legales que la CEBB y la SEBB son competentes para declarar la existencia de barreras burocráticas ilegales o irracionales que son denunciadas por los administrados al ver amenazado el normal desarrollo de sus actividades en el mercado. Ello, sin perjuicio de que, como se ha explicado, el universo de barreras legales incluya la totalidad de regulaciones emitidas por el Estado e incluso sus actuaciones, a través de sus distintos organismos y niveles de gobierno, algunas de las cuales no puedan ser cuestionadas a través del procedimiento de eliminación de barreras burocráticas, sino que pueden ser cuestionadas mediante otros mecanismos de control posterior de la regulación.

\section{EL SISTEMA DE ELIMINACIÓN DE BARRERAS BUROCRÁTICAS}

Como se ha podido adelantar, dentro de los mecanismos de control posterior destinados a que no existan barreras legales injustificadas que limiten la libre competencia, en el Perú se cuenta con un régimen legal orientado a desactivar medidas de la Administración Pública que reducen o eliminan el acceso o permanencia en el mercado de manera ilegal o irracional.

En la actualidad, este sistema se encuentra regulado principalmente en el DL 1256, cuya finalidad es

supervisar el cumplimiento del marco legal que protege los derechos a la libre iniciativa privada y la libertad de empresa, en beneficio de personas naturales o jurídicas, mediante la prevención y eliminación de barreras burocráticas ilegales y/o carentes de razonabilidad que restrinjan u obstaculicen el acceso o la permanencia de los agentes económicos en el mercado y/o que constituyan incumplimientos de las normas y/o principios que garantizan la simplificación administrativa con el objeto de procurar una eficiente prestación de servicios al ciudadano por parte de las entidades de la administración pública (Decreto Legislativo 1256, 2016, art. 1).

En ese sentido, este régimen limita y define el concepto de barrera burocrática de la siguiente manera:

[b]arrera burocrática: exigencia, requisito, limitación, prohibición y/o cobro que imponga cualquier entidad, dirigido a condicionar, restringir u obstaculizar el acceso y/o permanencia de los agentes económicos en el mercado y/o que puedan afectar a administrados en la tramitación de procedimientos administrativos sujetos a las normas y/o principios que garantizan la simplificación administrativa (Decreto Legislativo 1256, 2016, art. 3). 
Cabe recordar, entonces, que las barreras burocráticas pueden materializarse a través de actos administrativos, disposiciones administrativas o actuaciones materiales de la Administración Pública.

De este modo, las barreras burocráticas se encuentran referidas a las barreras legales originadas por el ejercicio de la función administrativa de las entidades públicas. No obstante, existen ciertas actuaciones estatales -que, si bien pueden constituir barreras legales, conforme a los conceptos explicados en las secciones precedentesexcluidas expresamente del concepto de barrera burocrática y, en consecuencia, no se encuentran bajo el ámbito de aplicación del sistema regulado por el DL $1256^{14}$.

\section{A. Importancia de la eliminación de barreras burocráticas}

La relevancia de la eliminación de barreras burocráticas se ve reflejada de distintas maneras. Desde el punto de vista de los derechos de los ciudadanos, como la propia finalidad del DL 1256 reconoce, además de velar por la prestación eficiente y simplificada de procedimientos administrativos, permite proteger los derechos a la libre iniciativa privada y la libertad de empresa. Al respecto, Ochoa Mendoza ha indicado lo siguiente:

[l]ibertad de iniciativa privada y de empresa tienen diferente contenido pero coinciden en el objetivo. La primera garantiza que la idea de negocio, de producto de la creatividad del empresario, no sea invalidada por algún tipo de intervención estatal que le diga qué hacer o cómo hacer el emprendimiento. La segunda garantiza que la actividad económica, una vez escogida, se desarrolle y organice libremente sin intervención externa a la voluntad del empresario. En ambos casos se persigue extender el principio de libertad que tiene todo ciudadano en su ámbito económico (2014, p. 11).

Como consecuencia de garantizar el ejercicio de los derechos indicados y la simplificación administrativa, se generan beneficios a los consumidores ante la presencia de un mayor número de ofertantes en el mercado, lo cual implica mejoras en la calidad y precio de los bienes a su disposición (Delgado Flores, 2012, p. 41).

Corresponde destacar la importancia y necesidad de implementar políticas de simplificación administrativa, debido a que las reglamentaciones administrativas excesivas o complejas pueden impedir la innovación. Asimismo, crean obstáculos innecesarios al comercio, la inversión y la eficiencia económica, e incluso amenazan la legitimidad de la política regulatoria y el Estado de Derecho (OCDE, 2011, p. 28).

Sumado a lo anterior, desde un punto de vista macroeconómico, la eliminación de barreras burocráticas permite promover la competitividad del país, en tanto busca reducir las trabas que afectan la inversión privada y, por lo tanto, el crecimiento económico. Tal como ha reconocido el Indecopi:

[I]a entrada de nuevas empresas y emprendimientos, así como el desarrollo de las empresas ya existentes, es fundamental para promover la competitividad y el crecimiento de un país, por lo que es importante que la regulación facilite el acceso y permanencia de empresas en los mercados, y no sea impuesta por las entidades de la Administración Pública sin razonabilidad o de manera ilegal $(2018$, p. 5).

En ese mismo sentido se ha pronunciado la OCDE al analizar las políticas de competencia en el Perú: "[e]n teoría, las recomendaciones de la CEBB relativas a la eliminación de barreras burocráticas contribuyen indirectamente a reducir los costos de competencia y las barreras de acceso al mercado" (2018, p. 95). Igualmente, el Estado peruano ha considerado que la emisión del DL 1256 se encontró justificada en que:

[...] los agentes económicos se siguen enfrentando en su día a día a diversas barreras burocráticas ilegales o carentes de razonabilidad, que obstaculizan su actividad empresarial y retrasan la ejecución de sus proyectos de inversión, además de debilitar la competencia como fuente principal de producción y crecimiento a largo plazo" (Exposición de Motivos del Decreto Legislativo 1256,2016 , p. 1).

14 Nos referimos a los supuestos previstos en la misma definición de barreras burocráticas prevista en el artículo 3 del DL 1256, los cuales son: (i) las medidas establecidas en leyes u otras normas con rango de ley y alcance nacional, emitidas al amparo de la función legislativa; (ii) las exigencias, requisitos, limitaciones, prohibiciones o cobros contenidos en contratos suscritos por una entidad, procesos de subasta o bases de algún tipo de concurso para contratar con el Estado; (iii) las omisiones, inacciones o cualquier inactividad de la administración pública; (iv) las tarifas o contraprestaciones por servicios prestados por el Estado o por empresas privadas o públicas, ajenos al ejercicio de la función administrativa; (v) el cobro de aranceles e impuestos y, en general, cualquier tributo no vinculado, así como los criterios para su determinación; (vi) las medidas fito y zoosanitarias; (vii) las controversias contencioso-tributarias; (viii) el cobro de arbitrios a personas naturales sin actividad económica; (ix) la declaración de nulidad de un acto administrativo por motivos de debido procedimiento; y, (x) la imposición de sanciones (2016). 
Por lo tanto, existen diversos intereses públicos en la eliminación de barreras burocráticas como mecanismo necesario para promover la competencia en el mercado y el bienestar de los ciudadanos.

\section{B. El procedimiento de eliminación de barre- ras burocráticas}

En atención a la importancia y los objetivos que se pueden alcanzar a través de la eliminación de barreras burocráticas, el DL 1256 establece una serie de herramientas destinadas a lograr tales fines, tanto desde el ámbito de la prevención como del control posterior de las medidas administrativas a través del procedimiento de eliminación de barreras burocráticas. Además, este dispositivo normativo prevé un régimen sancionador y correctivo aplicable a entidades, funcionarios, servidores públicos o cualquier persona que ejerza función administrativa.

Es en ese contexto que, con relación a este régimen normativo, se ha señalado que:

Perú es un study case [...] hoy día tenemos una normatividad muy moderna y que ha avanzado mucho; como señalaba, es única (no hay otro país que tenga una cosa parecida) y creo que más allá de sus limitaciones por la falta de recursos, ha conseguido avances importantes. Sin embargo es una tarea titánica: hay que luchar contra un monstruo muy grande y al que le crecen cabezas y tentáculos cada vez que se corta una cabeza o un tentáculo. Así son las barreras burocráticas que se crean y recrean todo el tiempo (Bullard Gonzáles, 2017, p. 273).

Precisamente, nos referiremos al procedimiento de eliminación de barreras burocráticas como mecanismo que permite la participación de los administrados en las acciones del Indecopi para permitir que las empresas puedan acceder y mantener su permanencia en el mercado. Sobre el particular, el artículo 7 del DL 1256 reconoce las modalidades de inicio de este procedimiento, diferenciando:

(i) El procedimiento iniciado a pedido de parte, mediante la presentación de una denuncia dirigida al Secretario Técnico de la CEBB, cumpliendo los requisitos establecidos en el artículo 20 de esta norma.

(ii) El procedimiento iniciado de oficio por decisión de la Secretaría Técnica de la CEEB, que también puede ser originado por la presentación de denuncias informativas formuladas por gremios empresariales, colegios profesionales, la Defensoría del Pueblo, entre otras instituciones, personas naturales o jurídicas.
Sin perjuicio de lo anterior, bajo ambas modalidades de inicio del procedimiento, de conformidad con el artículo 4 del DL 1256, resultan aplicables el principio de encausamiento del procedimiento y los principios reconocidos en el artículo IV del Título Preliminar del Texto Único Ordenado de la Ley del Procedimiento Administrativo General, aprobado mediante Decreto Supremo 004-2019-JUS (en adelante, LPAG), tales como los principios de impulso de oficio, informalismo, verdad material, entre otros. Es decir, incluso en los procedimientos iniciados a pedido de parte, los órganos competentes del Indecopi tienen el deber de dirigir e impulsar el procedimiento a efectos de verificar plenamente los hechos que sirven de motivo de sus decisiones.

Efectivamente, como en todo procedimiento administrativo, se hace de especial interés considerar la totalidad de hechos y cuestiones que permitan emitir un pronunciamiento conforme a derecho y que tutele de manera efectiva los derechos de los administrados. En el caso particular de los procedimientos de eliminación de barreras burocráticas, se tiene además la finalidad de promover la competencia y eficiencia en el mercado, así como velar por los intereses públicos subyacentes a este régimen legal.

\section{Metodología de análisis de posibles barre- ras burocráticas}

Ahora bien, el DL 1256 sistematiza la metodología general que se debe seguir en los procedimientos de eliminación de barreras burocráticas para analizar y determinar si las medidas administrativas constituyen o no barreras burocráticas que deban ser inaplicadas por ser ilegales o irracionales.

Dicha metodología establece que, en primer lugar, debe realizarse un análisis de legalidad de la medida. Conforme al artículo 14 del DL 1256, para determinar si la medida es legal o ilegal importa evaluar los siguientes tres aspectos:

(i) Si existen o no atribuciones conferidas por ley que autoricen a la entidad a establecer o aplicar la barrera burocrática bajo análisis.

(ii) Si la entidad siguió los procedimientos o formalidades que exige el marco legal vigente para la emisión o publicación de la disposición administrativa que materializa la barrera burocrática.

(iii) Si a través de la imposición o aplicación de la barrera burocrática se contravienen normas o principios de simplificación administrativa o cualquier dispositivo legal. 
De declararse la ilegalidad de barreras burocráticas materializadas en disposiciones administrativas, la CEBB o la SEBB disponen su inaplicación con efectos generales. En caso se declare la ilegalidad de barreras burocráticas materializadas en actos administrativos o actuaciones materiales, se dispone su inaplicación al caso concreto en favor denunciante.

En segundo lugar, de ser necesario continuar con la evaluación de la medida por haberse verificado su legalidad, en línea con los artículos 15 y siguientes DL 1256, se realizará un análisis de razonabilidad, siempre y cuando se presenten -de manera previa a la emisión de la resolución de admisión a trámite de la denuncia- indicios suficientes respecto a la carencia de razonabilidad de la misma.

La medida será irrazonable cuando (i) con ella no se busque tutelar un fin/interés público o no sea idónea para alcanzar el objetivo de la medida (es decir, sea una medida arbitraria); o, (ii) cuando no sea proporcional con los fines que busca tutelar o cuando no sea la opción menos costosa/gravosa para lograr tales fines (es decir, sea una medida desproporcionada).

Respecto a los efectos derivados de la declaración de barreras burocrática irracionales, el DL 1256 diferencia: (i) en los procedimientos iniciados de oficio referidos a barreras contenidas en disposiciones administrativas, se ordena la publicación de un extracto de la resolución correspondiente en el Diario Oficial El Peruano; y, (ii) en los procedimientos iniciados a pedido de parte (ya sea contenidos en disposiciones administrativas, actos administrativos o actuaciones materiales), se dispone su inaplicación al caso concreto en favor del denunciante.

\section{YO TAMBIÉN QUIERO DENUNCIAR: LAS EXIGENCIAS A LOS ADMINISTRADOS EN EL PROCEDIMIENTO DE ELIMINACIÓN DE BA- RRERAS BUROCRÁTICAS}

Como se ha indicado, el procedimiento de eliminación de barreras burocráticas puede iniciarse a pedido de parte o de oficio. Ambas modalidades permiten la participación de los administrados, pues incluso el procedimiento iniciado de oficio puede originarse por la presentación de denuncias informativas. Sin embargo, el DL 1256 prevé los requisitos y exigencias que deben cumplir los administrados para interponer una denuncia con el objetivo de iniciar este tipo de procedimientos; es decir, no resultan aplicables para la presentación de denuncias informativas para que la Secretaría Técnica de la CEBB inicie procedimientos de oficio.
Así, el artículo 20 del DL 1256, en concordancia con el artículo 26 del mismo cuerpo legal, establece los requisitos para admitir a trámite las denuncias para iniciar un procedimiento a pedido de parte, siendo estos los siguientes:

[p]ara interponer una denuncia, además del pago de la respectiva tasa, el denunciante debe identificar de manera concisa y/o presentar a través de su denuncia o anexos, los siguientes aspectos:

1. La(s) barrera(s) burocrática(s) materia de denuncia.

2. El medio de materialización: disposición administrativa, acto administrativo y/o actuación material. En caso de denunciar una disposición administrativa, el denunciante además debe identificar el párrafo, el artículo o parte pertinente en que se encuentra materializada la barrera burocrática.

3. La entidad (o entidades) que impone(n) y/o aplica(n) la(s) barrera(s) burocrática(s) materia de denuncia.

4. Los hechos, cuando la barrera burocrática se materializa en actos administrativos y/o actuaciones materiales.

5. Los fundamentos jurídicos que sustentan que la barrera burocrática denunciada es ilegal, de ser el caso.

6. Los indicios que sustentan la presunta carencia de razonabilidad de la barrera burocrática denunciada, de ser el caso.

7. Los medios probatorios que se requieran para acreditar lo afirmado en los literales anteriores, cuando corresponda (2016).

Como se puede observar, los requisitos indicados en los numerales 1 al 4 de la norma citada se encuentran dirigidos a identificar la(s) medida(s) y hechos denunciados, por lo que resultan necesarios para que se determine el objeto de la denuncia y, por lo tanto, del procedimiento.

Por su parte, los numerales 5 y 6 de la norma se encuentran vinculados al sustento necesario para justificar que las medidas denunciadas constituyen barreras burocráticas ilegales o irracionales, respectivamente. Evidentemente, el cumplimiento de estos requisitos requiere de un mayor esfuerzo por parte de los administrados para la admisión a trámite de sus posibles denuncias y para que, posteriormente, sean declaradas fundadas. No obstante, el estándar requerido para la admi- 
sión de la denuncia no implica el análisis de legalidad o razonabilidad de las medidas en dicho momento, pues ello formará parte de la evaluación y decisión que será emitida por la autoridad en el procedimiento.

Por último, el numeral 7 de la norma mencionada se refiere a la presentación de medios probatorios en aquellos casos en los que sea necesario, por lo que no representa mayor complejidad para los administrados, sino que les permite ejercer su derecho a ofrecer y a producir pruebas en los procedimientos administrativos de la manera en la que estimen más conveniente, en línea con su derecho al debido procedimiento.

Respecto a los requisitos de procedencia de las denuncias, el artículo 27 del DL 1256 se remite expresamente a los supuestos de improcedencia regulados en el Código Procesal Civil, cuyo artículo 427 señala las siguientes causales de improcedencia: (i) falta de legitimidad para obrar; (ii) falta de interés para obrar; (iii) caducidad del derecho; (iv) falta de conexión lógica entre los hechos y el petitorio; $y,(v)$ petitorio jurídica o físicamente imposible.

Finalmente, para que una denuncia contra barreras burocráticas sea declarada fundada, se deberá seguir la metodología de análisis comentada anteriormente para determinar si las medidas denunciadas constituyen barreras ilegales o irracionales. Con relación a este último aspecto, el DL 1256 no limita que el análisis a ser realizado por la CEBB o la SEBB deba restringirse a los fundamentos indicados en las denuncias de parte que dieran inicio al procedimiento de eliminación de barreras burocráticas, sino que prevé reglas particulares para la participación del denunciante y la entidad denunciada en el procedimiento.

Es por ello que las exigencias que impone el DL 1256 a los administrados para su participación como denunciantes en un procedimiento de eliminación de barreras burocráticas deben ser analizadas en función a la singularidad de este sistema. Para dichos efectos, a continuación abordaremos algunas reflexiones en torno a las exigencias impuestas a los administrados para la presentación y éxito de las denuncias de parte para la eliminación y/o inaplicación de barreras burocráticas, las cuales pueden constituir dificultades e incluso desincentivos para realizar este tipo de denuncias.

\section{A. Fundamentación jurídica para el análisis de legalidad}

El numeral 5 del artículo 20 del DL 1256, citado anteriormente, establece como un requisito de admisibilidad de la denuncia que los denunciantes desarrollen, en caso de invocarse la existencia de alguna barrera burocrática ilegal, los fundamentos jurídicos que sustenten la ilegalidad de la medida. Este requisito se encuentra vinculado con el análisis de legalidad que deberá realizar la autoridad como primer paso de la metodología prevista para evaluar si una medida administrativa constituye o no una barrera burocrática que deba ser eliminada por tratarse de una barrera ilegal contraria al ordenamiento jurídico.

Tomando en consideración que el artículo 21 del DL 1256 permite que en los procedimientos de eliminación de barreras burocráticas no se requiera de la participación de abogados, cabe preguntarse: ¿Deberá exigirse a los denunciantes desarrollar exhaustivamente las bases normativas a las que se refiere la denuncia? ¿El análisis de la CEBB o la SEBB deberá limitarse a los argumentos de legalidad expuestos en la denuncia?

En opinión que compartimos, Paredes Fiestas y Ugás Sobarzo han señalado que se trata de un análisis complejo, pues "[...] supone contrastar el acto o la disposición denunciada con todas las normas del ordenamiento jurídico peruano y no solo con las que fueron alegadas por el denunciante" (2014, p. 82), sin perjuicio de que deba salvaguardarse el derecho de defensa de la entidad denunciada (Luna, 2019, p. 57). Adicionalmente, al encontrarse este análisis íntimamente vinculado con el principio de legalidad en materia administrativa ${ }^{15}$, no se debe olvidar que:

[e]l principio de sujeción de la Administración a la legislación, denominado modernamente como 'vinculación positiva de la Administración a la Ley', exige que la certeza de validez de toda acción administrativa dependa de la medida en que pueda referirse a un precepto jurídico o que partiendo desde este, pueda derivársele como su cobertura o desarrollo necesario. El marco jurídico para la administración es un valor indisponible motu proprio, irrenunciable ni transigible (Morón Urbina, 2019, p. 78).

Estos aspectos son de especial relevancia si se toma en consideración los fines públicos e importancia del procedimiento de eliminación de barre-

15 Principio reconocido en el numeral 1.1 del artículo IV del Título Preliminar de la LPAG: "1.1. Principio de legalidad.- Las autoridades administrativas deben actuar con respeto a la Constitución, la ley y al derecho, dentro de las facultades que le estén atribuidas y de acuerdo con los fines para los que les fueron conferidas" (2019). 
ras burocráticas para promover la competencia y proteger los derechos a la libre iniciativa privada $y$ libertad de empresa, siendo que la CEBB y la SEBB cuentan con facultades suficientes para realizar acciones de oficio y encausar el procedimiento.

En ese sentido, en virtud al principio de legalidad y al ser competencia de la CEBB y la SEBB el aplicar y velar por el cumplimiento de la normativa en materia de eliminación de las barreras burocráticas, sostenemos que tales órganos deberían realizar un análisis en conjunto de todo el marco legal aplicable y no limitarse a los argumentos expuestos por el denunciante. Pese a lo anterior, no debe perderse de vista el importante rol de los administrados para advertir y sustentar la ilegalidad de las medidas que son objeto de denuncia.

\section{B. Indicios sobre la existencia de la barrera bu- rocrática irracional y la carga de la prueba para el análisis de razonabilidad}

Superado el análisis de legalidad, en caso se hayan presentado indicios suficientes sobre la irracionalidad de la(s) medida(s) denunciada(s), se procede con el análisis de razonabilidad, el cual se encuentra íntimamente vinculado a la verificación de que la medida denunciada cumple con el principio de razonabilidad, reconocido en el numeral 1.4 del artículo IV del Título Preliminar de la LPAG ${ }^{16}$. Este último principio es asimilado al principio de proporcionalidad en materia constitucional ${ }^{17}$ y postula la adecuación entre medios y fines, de modo que la Administración Pública no debe imponer cargas u obligaciones más gravosas que las que sean indispensables para cumplir con las exigencias del interés público que se busca tutelar a través de cada actuación administrativa en específico (Danós Ordóñez, 1999, p. 240).

Para entrar a esta etapa de la metodología de análisis, además del requisito de admisibilidad establecido en el numeral 6 del artículo 20 del DL 1256, el artículo 15 de esta misma ley condiciona expresamente la evaluación de la razonabilidad de las medidas denunciadas al hecho de que se hubieran presentado indicios suficientes respecto a la carencia de razonabilidad en la denuncia y hasta antes de que se emita la resolución de admisión a trámite de esta.

El artículo 16 del DL 1256 recoge un listado no taxativo de supuestos que no serán considerados como indicios suficientes. Estos son, cuando los argumentos del denunciante: (i) no se encuentren referidos a la barrera burocrática cuestionada; (ii) tengan como finalidad cuestionar la pertinencia de una política pública; (iii) se trate de alegaciones o afirmaciones genéricas; $y$, (iv) se alegue como único argumento que la medida genera costos.

Así las cosas, conforme a la normativa vigente, el denunciante necesariamente debe aportar indicios sobre la falta de razonabilidad de la medida denunciada, a efectos de que se lleve a cabo el análisis correspondiente. De cumplirse ello, de acuerdo al artículo 18 del DL 1256, la entidad denunciada tiene la carga de probar que la medida denunciada no es arbitraria ni desproporcional. El motivo de la inversión de la carga de la prueba se debe a que es la entidad pública denunciada la que conoce si existió o no, entre otros aspectos, algún interés público que justificó la medida y los beneficios a la comunidad que se espera obtener; que las cargas impuestas son adecuadas o razonables considerando los fines; y que la exigencia cuestionada es menos gravosa en relación con las demás opciones existentes.

El condicionamiento del análisis de razonabilidad a la presentación de indicios ha sido cuestionado anteriormente por distintos autores, al sostener que tal exigencia es innecesaria:

16 Este principio del procedimiento administrativo hace referencia a que

1.4. Principio de razonabilidad.- Las decisiones de la autoridad administrativa, cuando creen obligaciones, califiquen infracciones, impongan sanciones, o establezcan restricciones a los administrados, deben adaptarse dentro de los límites de la facultad atribuida y manteniendo la debida proporción entre los medios a emplear y los fines públicos que deba tutelar, a fin de que respondan a lo estrictamente necesario para la satisfacción de su cometido (Ley del Procedimiento Administrativo General [LPAG], 2019).

17 A mayor ahondamiento, el Tribunal Constitucional del Perú ha señalado:

[e]l principio de razonabilidad o proporcionalidad es consustancial al Estado Social y Democrático de Derecho, y está configurado en la Constitución en sus artículos $3^{\circ}$ y $43^{\circ}$, y plasmado expresamente en su artículo 200 , último párrafo. Si bien la doctrina suele hacer distinciones entre el principio de proporcionalidad y el principio de razonabilidad, como estrategias para resolver conflictos de principios constitucionales y orientar al juzgador hacia una decisión que no sea arbitraria sino justa; puede establecerse, prima facie, una similitud entre ambos principios, en la medida que una decisión que se adopta en el marco de convergencia de dos principios constitucionales, cuando no respeta el principio de proporcionalidad, no será razonable. En este sentido, el principio de razonabilidad parece sugerir una valoración respecto del resultado del razonamiento del juzgador expresado en su decisión, mientras que el procedimiento para llegar a este resultado sería la aplicación del principio de proporcionalidad con sus tres subprincipios: de adecuación, de necesidad y de proporcionalidad en sentido estricto o ponderación (Sentencia recaída en el expediente 2192-2004-AA/TC, 2004). 
[d]e suerte que el derecho de los denunciantes a obtener una decisión sobre la razonabilidad de una barrera parecería reducirse, en nuestro país, a una especie de intercambio con efectos impredecibles, que podría resumirse de la siguiente manera: Si tú me das indicios, yo te doy razonabilidad. Ello, sin embargo, nos parece una carga innecesaria, ya que quien debería demostrar si un cobro, requisito, exigencia, prohibición o limitación no es arbitraria ni desproporcionada es la misma entidad que creó la barrera, de manera que única y exclusivamente sea ella quien ofrezca los elementos de juicio que permitan un correcto análisis de razonabilidad (Guzmán Chuquillanqui, 2019, p. 204).

Paredes Fiestas y Ugás Sobarzo observaron, por su parte, este aspecto incluso antes de la publicación del DL 1256 :

[...] la carga de la prueba impuesta a los denunciantes para cuestionar la carencia de razonabilidad de un acto o disposición administrativa es elevada pues debe estar debidamente motivada para crear convicción en los comisionados de la CEB o en los vocales de la Sala. Incluso para acreditar el indicio de desproporción se necesita que el denunciante argumente adecuadamente qué otras medidas hubieran sido igualmente satisfactorias para proteger el interés público.

Cabe recordar que en los procedimientos seguidos ante el Indecopi no es necesario contar con un abogado, por lo que los denunciantes podrían tener dificultades para presentar indicios suficientes sin un asesoramiento adecuado (2014, p. 91).
No son pocos los procedimientos en los que la CEBB o la SEBB estiman que no corresponde realizar el análisis de razonabilidad de las medidas objeto de denuncia, al considerar que el denunciante no ha presentado indicios suficientes. De manera general, y sin entrar en el detalle de cada procedimiento específico, se puede observar dicha tendencia en múltiples pronunciamientos de la CEBB y la SEBB en los últimos años ${ }^{18}$.

Si bien no es objeto de la presente investigación observar el detalle de los indicios o argumentos de razonabilidad esbozados en cada uno de los casos de los últimos años en los que se ha declarado que no corresponde realizar el análisis de razonabilidad por falta de indicios, es posible observar que se trata de un criterio reiterado tanto por la CEBB como la SEBB. En la medida que se trata de una dificultad efectiva que no puede ser superada por los administrados en todos los casos, ya sea por el criterio utilizado por la autoridad o por falta de asesoría en la presentación de las denuncias, a pesar de que -como se ha mencionado- el procedimiento de eliminación de barreras burocráticas no requiera de la participación de abogados.

En función a lo anterior, la aplicación restrictiva del artículo 15 del DL 1256 no parecería ser concordante con la importancia del procedimiento de eliminación de barreras burocráticas para permitir contar con una política regulatoria basada en principios de racionalidad y proporcionalidad. A su vez, la aplicación restrictiva de dicha exigencia legal podría implicar un desconocimiento de los principios administrativos de impulso de oficio ${ }^{19}$, informalismo ${ }^{20}$ y verdad material ${ }^{21}$. Ello, debido a que, en línea con la LPAG, las autoridades administrativas

18 A manera de ejemplo, podemos mencionar las siguientes resoluciones de CEBB y la SEBB: Resolución 0072-2020/ CEB-INDECOPI; Resolución 0060-2020/CEB-INDECOPI; Resolución 0019-2020/CEB-INDECOPI; Resolución 00102020/CEB-INDECOPI; Resolución 0248-2019/CEB-INDECOPI; Resolución 0204-2019/CEB-INDECOPI; Resolución 0002-2019/CEB-INDECOPI; Resolución 0046-2020/SEL-INDECOPI; Resolución 0009-2020/SEL-INDECOPI; Resolución 0004-2020/SEL-INDECOPI; Resolución 0627-2019/SEL-INDECOPI; Resolución 0072-2019/SEL-INDECOPI.

19 El principio de impulso de oficio establece que

1.3. Principio de impulso de oficio.- Las autoridades deben dirigir e impulsar de oficio el procedimiento y ordenar la realización o práctica de los actos que resulten convenientes para el esclarecimiento y resolución de las cuestiones necesarias (LPAG, 2019).

20 El principio de informalismo establece que

1.6. Principio de informalismo.- Las normas de procedimiento deben ser interpretadas en forma favorable a la admisión y decisión final de las pretensiones de los administrados, de modo que sus derechos e intereses no sean afectados por la exigencia de aspectos formales que puedan ser subsanados dentro del procedimiento, siempre que dicha excusa no afecte derechos de terceros o el interés público (LPAG, 2019).

21 El principio de verdad material establece que

1.11. Principio de verdad material.- En el procedimiento, la autoridad administrativa competente deberá verificar plenamente los hechos que sirven de motivo a sus decisiones, para lo cual deberá adoptar todas las medidas probatorias necesarias autorizadas por la ley, aun cuando no hayan sido propuestas por los administrados o hayan acordado eximirse de ellas.

En el caso de procedimientos trilaterales la autoridad administrativa estará facultada a verificar por todos los medios disponibles la verdad de los hechos que le son propuestos por las partes, sin que ello signifique una sustitución del deber probatorio que corresponde a estas. Sin embargo, la autoridad administrativa estará obligada a ejercer dicha facultad cuando su pronunciamiento pudiera involucrar también al interés público (LPAG, 2019). 
pueden realizar, entre otras, acciones de oficio destinadas a conocer la verdad material sobre la razonabilidad de las medidas denunciadas.

Adicionalmente, la LPAG contiene una serie de disposiciones que permiten advertir que la naturaleza del procedimiento administrativo habilita la realización de actuaciones flexibles para emitir pronunciamientos conforme a la verdad material y en tutela efectiva de los derechos de los administrados, lo cual resulta contradictorio con la exigencia del DL 1256 para que la presentación de indicios sobre la carencia de razonabilidad pueda ser realizada únicamente de manera previa a la admisión a trámite de la denuncia. Dicha exigencia resulta muy limitativa y contraria a, por ejemplo, las siguientes normas generales:

\section{Artículo 172.- Alegaciones}

172.1. Los administrados pueden en cualquier momento del procedimiento, formular alegaciones, aportar los documentos $\mathrm{u}$ otros elementos de juicio, los que serán analizados por la autoridad, al resolver.

(...)

\section{Artículo 174.- Actuación probatoria}

174.1 Cuando la administración no tenga por ciertos los hechos alegados por los administrados o la naturaleza del procedimiento lo exija, la entidad dispone la actuación de prueba, siguiendo el criterio de concentración procesal, fijando un período que para el efecto no será menor de tres días ni mayor de quince, contados a partir de su planteamiento. Sólo podrá rechazar motivadamente los medios de prueba propuestos por el administrado, cuando no guarden relación con el fondo del asunto, sean improcedentes o innecesarios (LPAG, 2019).

Por lo tanto, es posible observar que las exigencias que impone el DL 1256 para presentar indicios suficientes y que se proceda con el análisis de razonabilidad deberían ser objeto de un cambio de criterio por parte de la CEBB y la SEBB a un criterio no restrictivo y orientado analizar la razonabilidad de las medidas denunciadas por los administrados, cuya participación en estos procedimientos resulta de gran importancia para contribuir a mejorar la política regulatoria y el desarrollo del país. En todo caso, tal exigencia también podría ser objeto de una reforma legislativa que busque fortalecer este régimen con la finalidad de permitir, sin lugar a dudas, el análisis y la posible eliminación o inaplicación de las barreras burocráticas carentes de razonabilidad.

\section{CONCLUSIONES}

El cumplimiento de los objetivos del Estado peruano para garantizar y proteger los derechos consti- tucionales económicos de los ciudadanos y, consiguientemente, aumentar la competitividad e inversiones en el país requiere de la implementación de políticas que permitan la libre competencia en el mercado.

Como parte importante de dichas políticas, es necesario contar con regulaciones justificadas y eficientes. Es decir, contar con un orden normativo que no limite de manera excesiva o innecesaria el desarrollo de las actividades económicas; caso contrario, el Estado se impondría barreras legales que restringirían ilegítimamente la entrada de nuevas iniciativas privadas al mercado, así como para las empresas constituidas que podrían ver afectado el desarrollo de sus operaciones.

El presente análisis ha permitido destacar que las barreras legales no son la única clase de dificultades que enfrentan los privados para acceder y mantenerse en el mercado. En efecto, la participación en el mercado podría verse afectada por comportamientos anticompetitivos y desleales de empresas competidoras, los cuales califican como barreras estratégicas que pueden ser investigadas y sancionadas bajo las reglas y prohibiciones establecidas en la LRCA y la LRCD.

Asimismo, las características y situación de cada mercado específico también imponen barreras estructurales para el desarrollo de las actividades económicas. Es dentro de estas que se encuentran las barreras legales, pero también las barreras económicas que son consideradas por algunos autores y autoridades como barreras naturales por tener su origen en las condiciones generadas por el propio mercado para realizar cada actividad económica particular. Las barreras estructurales no son negativas.

Ahora bien, a efectos de que la libre competencia en el país no se vea afectada por barreras legales ineficientes o manifiestamente contrarias a los intereses públicos y privados, el ordenamiento jurídico peruano prevé mecanismos de control de la regulación, tanto de manera previa a su emisión como de manera posterior.

Precisamente, un mecanismo de control posterior de la regulación al que pueden acceder los ciudadanos es el procedimiento de eliminación de barreras burocráticas ante la CEBB del Indecopi, mediante el cual se puede alcanzar la eliminación o inaplicación de medidas administrativas ilegales e irracionales que puedan afectar la entrada o permanencia en el mercado; así como dificultar la tramitación de procedimientos administrativos. Este procedimiento es, entonces, de gran relevancia. Permite la participación de los ciudadanos en 
la misión del Estado de lograr contar con políticas regulatorias de calidad que permitan aumentar la competitividad del país, la competencia en el mercado y por lo tanto, el bienestar común al contar con mayores ofertantes en el mercado y con procedimientos administrativos simplificados.

Sin perjuicio de tal relevancia, la normativa aplicable a dicho procedimiento impone ciertas exigencias a los administrados que denuncien barreras burocráticas, a fin de que se declare su ilegalidad o irracionalidad. No obstante, es posible sostener y proponer a la CEBB y a la SEBB que la interpretación de tales exigencias debería estar orientada a realizar un análisis total de la legalidad y razonabilidad de las medidas denunciadas por los administrados, tomando en consideración:

(i) La aplicación de los principios y normas generales a todo procedimiento administrativo;

(ii) El cumplimiento de las competencias otorgadas a los órganos mencionados para la eliminación de barreras burocráticas de oficio;

(iii) La no obligatoriedad de la participación de abogados en el procedimiento de eliminación de barreras burocráticas;

(iv) Los fines, alcances y relevancia del procedimiento de eliminación de barreras burocráticas; $y$,

(v) La importancia de la participación de la ciudadanía en el desarrollo de la calidad regulatoria en el país, siendo evidente que los administrados no cuentan con ningún incentivo negativo para presentar denuncias injustificadas contra barreras burocráticas.

\section{REFERENCIAS}

Bullard Gonzales, A. (2017). Algunos aspectos relevantes de la Nueva Ley de Prevención y Eliminación de Barreras Burocráticas. Derecho \& Sociedad, (49), 271-274.

Coloma, G. (2002). Prácticas horizontales exclusorias y defensa de la competencia. Universidad del Centro de Estudios Macroeconómicos de Argentina (Universidad del CEMA).

Comisión de Dumping, Subsidios y Eliminación de Barreras Comerciales No Arancelarias del Indecopi (2020). Guía informativa sobre el procedimiento de eliminación de barreras comerciales no arancelarias. https://www.indecopi. gob.pe/documents/1902049/4145241/Gu\% C3\%ADa+sobre+Barreras+Comerciales+No+
Arancelarias.pdf/75d3c6db-a057-6ae1-0222e82f825c3cf8

Delgado Flores, E. (2012). Propuesta de reforma del sistema de eliminación de barreras burocráticas. Revista de Actualidad Mercantil, (1), 41-44.

Danós Ordóñez, J. (1999). Comentarios al proyecto de la Nueva Ley de Normas Generales de Procedimientos Administrativos. THËMISRevista de Derecho, (39), 237-292. http://revistas.pucp.edu.pe/index.php/themis/article/ view/10435

Flint Blanck, P. (2002). Tratado de defensa de la libre competencia: estudio exegético del Decreto Legislativo 701. Fondo Editorial de la Pontificia Universidad Católica del Perú.

Guimaray Morales, A. (11 de mayo de 2018). Eliminación de Barreras Burocráticas. Comisión de Eliminación de Barreras Burocráticas. http://www.congreso.gob.pe/Docs/DGP/CCEP/ files/agenda2017-2018/files/ppt-conf_simpli ficaci\%C3\%B3n_adm_-alvaro_guimaray.pdf.

Guzmán Chuquillanqui, A. (2019). Breve reflexión sobre la necesidad de presentar indicios suficientes de carencia de razonabilidad en el procedimiento de eliminación de barreras burocráticas. Vox Juris, 37(2), 197-208. https://doi. org/10.24265/voxjuris.2019.v37n2.14

Instituto Nacional de Defensa de la Competencia y de la Protección de la Propiedad Intelectual [Indecopi] (2018). El impacto económico de la imposición de barreras burocráticas en el Perú. Observatorio de Mercados, 13(38), 1-40. https://www.indecopi.gob.pe/documents/ 20182/3026558/20190523 Observatorio Na cional_+Barreras_2018.pdf/d4368eae-de87fd78-ece3-aOfOaafe756c

Luna, L. (2019). Serie de Módulos Instruccionales. 01-2019. Eliminación de Barreras Burocráticas. Escuela Nacional del Indecopi.

Morón Urbina, J. C. (2019). Comentarios a la Ley del Procedimiento Administrativo General. Gaceta Jurídica.

Ochoa Mendoza, F. (2014). Fundamentos del Procedimiento de Eliminación de Barreras Burocráticas. Revista de la Competencia y la Propiedad Intelectual del Indecopi, 10(19), 1-56. https://revistas.indecopi.gob.pe/index.php/ rcpi/article/view/10 
Organización para la Cooperación y el Desarrollo Económicos [OCDE] (2005). Policy Roundtables: Barriers to Entry. https://www.oecd.org/ regreform/sectors/36344429.pdf.

(2011). Regulatory Policy and Governance: Supporting Economic Growth and Serving the Public Interest. http://www.congreso.es/docu/ docum/ddocum/dosieres/sleg/legislatura_10/ spl_101/pdfs/59.pdf.

(2016). Estudios de la OCDE en Reforma Regulatoria. Política Regulatoria en el Perú. Uniendo el marco para la calidad regulatoria. https://www.oecd.org/gov/regulatory-policy/ Poli\%CC\%81tica-Regulatoria-en-el-Peru\%CC\% 81-aspectos-clave.pdf.

(2018). Exámenes inter-pares de la OCDE y el BID sobre el derecho y política de competencia: Perú. https://www.oecd.org/daf/competition/ PERU-Peer-Reviews-of-Competition-Law-andPolicy-SP-2018.pdf.

(2020). Indicators of Regulatory Policy and Governance: Latin America 2019, Peru. https:// www.oecd.org/gov/regulatory-policy/Perucountry-profile-regulatory-policy-en.pdf.

Paredes Fiestas, G., \& Ugás Sobarzo, S. (2014). El análisis de razonabilidad a través de los pronunciamientos del Indecopi: cómo evitar medidas impuestas utilizando el "de tin marin de don pingüe". Revista de la Competencia y de la Propiedad Intelectual del Indecopi, 10(19), 79105. https://revistas.indecopi.gob.pe/index. php/rcpi/article/view/13

Paredes, M., \& Tarziján, J. (2006). Organización industrial para la estrategia empresarial, (2da ed.). Pearson Educación.

Patroni Vizquerra, Ú. (2011). Eliminar barreras burocráticas, la otra cara de la reforma del Estado. Revista de Derecho Administrativo, (10), 291-307.

Posner, R. A. (2001). Antitrust Law (2da ed.). University of Chicago Press.

Stigler, G. (1968). Barriers to Entry, Economies of Scale, and Firm Size. En The Organization of Industry (pp. ss.-ss.). Richard D. Irwin, Inc.

\section{LEGISLACIÓN, JURISPRUDENCIA Y OTROS DOCU- MENTOS LEGALES}

Comisión de Defensa de la Libre Competencia del Indecopi, 12 de octubre de 2016, Resolución 078-
2016/CLC-INDECOPI, Expediente 008-2010/ CLC (Perú).

Comisión de Defensa de la Libre Competencia del Indecopi, 3 de mayo de 2010, Resolución 0262010/CLC-INDECOPI, Expediente 009-2008/ CLC (Perú).

Comisión de Eliminación de Barreras Burocráticas del Indecopi, 4 de enero de 2019, Resolución 002-2019/CEB-INDECOPI, Expediente 0001302017/CEB (Perú).

Comisión de Eliminación de Barreras Burocráticas del Indecopi, 23 de abril de 2019, Resolución 204-2019/CEB-INDECOPI, Expediente 0002772018/CEB (Perú).

Comisión de Eliminación de Barreras Burocráticas del Indecopi, 21 de mayo de 2019, Resolución 248-2019/CEB-INDECOPI, Expediente 0003752018/CEB (Perú).

Comisión de Eliminación de Barreras Burocráticas del Indecopi, 10 de enero de 2020, Resolución 010-2020/CEB-INDECOPI, Expediente 0002702019/CEB (Perú).

Comisión de Eliminación de Barreras Burocráticas del Indecopi, 14 de enero de 2020, Resolución 019-2020/CEB-INDECOPI, Expediente 0002602019/CEB (Perú).

Comisión de Eliminación de Barreras Burocráticas del Indecopi, 14 de febrero de 2020, Resolución 060-2020/CEB-INDECOPI, Expediente 000238-2019/CEB (Perú).

Comisión de Eliminación de Barreras Burocráticas del Indecopi, 25 de febrero de 2020, Resolución 072-2020/CEB-INDECOPI, Expediente 000256-2019/CEB (Perú).

Decreto Legislativo 1044, Decreto Legislativo que aprueba la Ley de Represión de la Competencia Desleal, Diario Oficial El Peruano, 26 de junio de 2008 (Perú).

Decreto Legislativo 1212, Decreto Legislativo que refuerza las facultades sobre eliminación de barreras burocráticas para el fomento de la competitividad, Diario Oficial El Peruano, 24 de septiembre de 2015, (Perú).

Decreto Legislativo 1256, Decreto Legislativo que aprueba la Ley de Prevención y Eliminación de Barreras Burocráticas, Diario Oficial El Peruano, 8 de diciembre de 2016 (Perú). 
Decreto Legislativo 1310, Decreto Legislativo que aprueba medidas adicionales de simplificación administrativa, Diario Oficial El Peruano, 30 de diciembre de 2016 (Perú).

Decreto Legislativo 1448, Decreto Legislativo que modifica el artículo 2 del Decreto Legislativo 1310, Decreto Legislativo que aprueba medidas adicionales de simplificación administrativa, y perfecciona el marco institucional y los instrumentos que rigen el proceso de mejora de calidad regulatoria, Diario Oficial El Peruano, 16 de septiembre de 2018, (Perú).

Decreto Supremo 008-2006-JUS, Decreto Supremo que aprueba el Reglamento de la Ley Marco para la Producción y Sistematización Legislativa, Diario Oficial El Peruano, 24 de marzo de 2006 (Perú)

Decreto Supremo 061-2019-PCM, Decreto Supremo que aprueba el Reglamento para la aplicación del Análisis de Calidad Regulatoria de procedimientos administrativos establecido en el artículo 2 del Decreto Legislativo $N^{\circ} 1310$ Decreto Legislativo que aprueba medidas adicionales de simplificación administrativa, Diario Oficial El Peruano, 5 de abril de 2019 (Perú).

Exposición de Motivos del Decreto Legislativo 1256. http://www.congreso.gob.pe/Docs/comisiones2016/ConstitucionReglamento/files/ exposici\%C3\%B3n_de_motivos_dl_1256.pdf.

Ley 26889, Ley Marco para la Producción y Sistematización Legislativa, Diario Oficial El Peruano, 10 de diciembre de 1997 (Perú).

Resolución Directoral 008-2016-JUS/DGDOJ, que aprueba la "Guía sobre la calidad normativa y publicación de proyectos normativos", 25 de agosto de 2016. https://www.minjus.gob.pe/ wp-content/uploads/2016/09/MINJUS-DGDOJ-Guia-sobre-la-calidad-normativa-y-publicacion-de-proyectos-normativos.pdf.

Sala Especializada en Eliminación de Barreras Burocráticas del Tribunal de Defensa de la Competencia y de la Propiedad Intelectual, 14 de marzo de 2019, Resolución 0072-2019/SELINDECOPI, Expediente 0262-2017/CEB (Perú).

Sala Especializada en Eliminación de Barreras Burocráticas del Tribunal de Defensa de la Com- petencia y de la Propiedad Intelectual, 30 de diciembre de 2019, Resolución 0627-2019/ SEL-INDECOPI, Expediente 000014-2019/CEB (Perú).

Sala Especializada en Eliminación de Barreras Burocráticas del Tribunal de Defensa de la Competencia y de la Propiedad Intelectual, 9 de enero de 2020, Resolución 0004-2020/SEL-INDECOPI, Expediente 077-2017/CEB-INDECOPIJUN (Perú).

Sala Especializada en Eliminación de Barreras Burocráticas del Tribunal de Defensa de la Competencia y de la Propiedad Intelectual, 9 de enero de 2020, Resolución 0009-2020/SEL-INDECOPI, Expediente 000243-2017/CEB (Perú).

Sala Especializada en Eliminación de Barreras Burocráticas del Tribunal de Defensa de la Competencia y de la Propiedad Intelectual, 3 de febrero de 2020, Resolución 0046-2020/SEL-INDECOPI, Expediente 000331-2018/CEB (Perú).

Secretaría Técnica de la Comisión de Defensa de la Libre Competencia del Indecopi (2004). Informe 035-2004-INDECOPI/ST-CLC. https://www. indecopi.gob.pe/documents/20182/143803/ inf035-2004.pdf.

Texto Único Ordenado de la Ley 27444, Ley del Procedimiento Administrativo General, aprobado mediante Decreto Supremo 004-2019JUS, Diario Oficial El Peruano, 25 de enero de 2019 (Perú).

Texto Único Ordenado de la Ley de Represión de Conductas Anticompetitivas, aprobado mediante Decreto Supremo 030-2019-PCM, Diario Oficial El Peruano, 19 de febrero de 2019 (Perú).

Texto Único Ordenado del Código Procesal Civil, aprobado mediante Resolución Ministerial 1093-JUS, y sus modificatorias, Diario Oficial EI Peruano, 23 de abril de 1993 (Perú).

Tribunal Constitucional [T.C.], 25 de agosto de 2010, sentencia recaída en el Expediente 00142009-PI/TC (Perú).

Tribunal Constitucional del Perú [T.C.], 11 de octubre de 2004, sentencia recaída en el Expediente 2192-2004-AA/TC (Perú). 